\title{
Взаимодействие права Республики Казахстан \\ и международного права
}

\section{О.Н. Сафонова}

Взаимодействие национального права Республики Казахстан (РК) и международного права, как любой процесс взаимовлияния явлений, воздействия их друг на друга, обусловлен рядом объективных и субъективных факторов. Думается, что первым объективным фактором такого взаимодействия является наличие двух самостоятельных правовых систем. В условиях сушествования в составе СССР Казахская ССР, как и каждая республика - член федерации, могла осуществлять свою международную правосубъектность, но на практике ее содержание было незначительным и весьма скудным ${ }^{1}$. Только в условиях обретения суверенитета и государственной независимости Республики Казахстан можно говорить о реальном взанмодействии двух правовых систем.

Обе правовые системы выступают как средства регуляции и координации. В связи с этим считаю, что следующим объективным фактором их взаимодействия выступает единая система общественных отношений. Для взаимодействия двух явлений необходимо наличие определенного пространства или сферы соприкосновения. В современный период все сложнее разделить национально-правовые отношения и международно-правовые отношения. Международным правом регулируются национально-правовые отношения (международные стандарты в области защиты прав человека, заключения сделок, бухгалтерского учета и в других сферах общественной жизни). Некоторые международные отношения в свою очередь регулируются нормами национального права (порядок заключения международных договоров, деятельности дипломатических представительств и др.).

Среди субъективных факторов можно назвать особенности национальной правовой системы Республики Казахстан, геополитическое, социально-экономическое положение нашего государства, уровень культуры и правосознание народа и другие.

Теоретические аспекты проблемы взаимодействия национального и международного права нашли отражение как в нашей стране, так

${ }^{1}$ Сарсельбаев M.A. Международное право в истории Казахстана и Средней Азии. Алматы, Ана тілі, 1991 г, 152 c. 
и за рубежом. Советская юридическая наука не обходила своим вниманием проблему соотношения национального и международного права, ее исследование проведено целым рядом известных ученых в области международно-правовой науки. ${ }^{2}$ Причем исследования по данной теме велись в основном юристами-международниками, а не теоретиками права. В разработке вопросов имплементации преобладал классовый подход с акцентом на превосходство и исключительность социалистической правовой системы. Сегодня необходимы переосмысление и новые решения многих теоретических и практических аспектов данной проблемы. Ее исследование возможно и на основе источниковой базы международного права и казахстанского законодательства.

Казахстан - молодое суверенное государство, появившееся и формируюшееся в 90-е Гг., объявленные $\mathrm{OOH}$ десятилетием международного права, в связи с этим влияние международного права на наше национальное право огромно, его невозможно переоценить.

"Под его (международного права - Авт.) влиянием в национальном праве возникают новые нормы, изменяются либо отменяются существующие, то есть, оказывая помощь международному праву с целью реализации его норм, национальное право подвергается изменениям, вызванным необходимостью исполнения норм международного права", - пишет Р.А. Мюллерсон ${ }^{3}$. Характер влияния международного права на внутригосударственное право зависит, прежде всего, от сущности и содержания последнего. РК провозгласила приверженность принципам международного права в проведении внутренней и внешней политики и формировании базы текущего законодательства. На сегодня практически все цивилизованные государства считают необходимым приведение своих правовых систем в соответствие с основными принципами международного права. Как известно, основополагающим принципом международного права является принцип мирного сосуществования государств. Его реализа-

2 Блищенко И.П. Международное и внутригосударственное право. М., 1960 г., 239 с. Буткевич В.Г. Соотношение внутригосударственного и международного права. Киев. Вища школа, 1981 г., 311 с. Игиатенко Г.В. Взаимодействие внутригосударственного и международного права. Свердловск, 1989. 289 с. Мюллерсон Р.A. Соотношение международного и национального права. М., Международные отношения, 1982 г., 136 с. Миронов Н.В. Советское законодательство и международное право. М., Международные отношения, 1968 г., 197 с.

3

Мюллерсон Р.A. Цит соч. С.55 
ция в РК находит свое отражение в Конституции Республики Казахстан, международных договорах, текущем законодательстве и в реальных шагах нашего государства по обретению статуса безъядерного государства, мирных инициативах в ООН, участии в мирном урегулировании международных споров.

Большое значение имеет влияние международных стандартов прав человека на конституционный статус личности в РК. На текущий момент наше законодательство в этой сфере уже, в основном, приведено в соответствие с Всеобщей декларацией прав человека 1948 г., Пактами о политических и социально-экономических правах 1966г., Конвенцией о правах ребенка 1989 г. и другими. Но этот процесс не завершен, нам еще предстоит присоединиться к основным международным документам по правам человека. Международное право оказывает влияние на появление в праве РК и всех других норм и принципов, способствующих укреплению и развитию сотрудничества государств, а также утверждению наиболее передовых технических норм. Это связано, прежде всего, с изменениями и дополнениями в текушее законодательство в связи с присоединением к ряду многосторонних конвенций. Например, коренным образом изменилось наше таможенное законодательство после присоединения PК к Таможенной конвенции о международной перевозке грузов с применением книжки МПД 1975 г. и вступления в 1992 г. в СТС.

Таможенное дело в нашей стране развивается в направлении гармонизации и унификации с общепринятыми в международной практике нормами и стандартами. Во многих случаях торговые соглашения, заключенные РК и другими странами, оказывают влияние на издание соответствующих внутригосударственных норм относительно поставок экспортной и импортной продукции, перевозки и распределения товаров и др.

Соглашения о предоставлении займов и кредитов влекут за собой издание законодательных актов РК, относящихся к области финансового права. Например, Закон "О внешнем заимствовании и управлении внешним долгом" от 10.04.1997 г., Закон "О валютном регулировании" от 24.12.1996 г., Постановление Кабинета Министров РК 139 от 08.02.1995 г., "О мерах по упорядочиванию привлечения иностранных кредитов в РК" и др. Соглашения об оказании экономической и технической помощи влияют на появление новых форм гражданского права Республики Казахстан (Указ Президента РК, имеюший силу закона, "О лицензировании" от 17.04.1995 г. и др.). 
Используются следующие формы приведения национального законодательства в соответствие с нормами международного права:

разработка и принятие принципиально новых законодательных актов, ранее не известных правовой системе РК;

принятие законов, заменяющих ранее действовавшие или существенно изменяющих их нормативное содержание;

принятие актов, вносящих частичные изменения и дополнения в ранее действующие законодательные акты;

подтверждение в национальных нормативных актах некоторых обычных норм международного права.

Говоря о влиянии международного права на казахстанское право, следует затронуть проблему пробельности и аналогии права. В казахстанском праве существует понятие "аналогии закона" и "аналогии права". Когда отношения, по поводу которых возник спор, не урегулированы ни нормами гражданского права, ни договором сторон, для внесения определенности во взаимоотношения участников спора применяют аналогию закона, если таковой законодательный акт имеется. При невозможности применить аналогию закона применяют аналогию права, т.е. к правоотношению применяют общие наччала и принципы правового регулирования соответствующей отрасли права. Это служит средством восполнения пробелов в праве. Мы знаем, что в публичных отраслях права аналогию права нельзя применять, но что касается цивилистики, то можно внести следующее предложение: вместо того, чтобы в описанных выше случаях применять аналогию закона или аналогию права, гораздо убедительнее в решении суда сделать ссылку на статью международного договора, стороной которого является РК, т.к. такой международный договор является частью права страны.

В доктрине и практике международных отношений принято выделять "мягкое право". По своей форме к нему относятся итоговые документы, декларации, заявления, программы международных конференций и встреч, а также-некоторые решения международных организаций. С их помощью регулируются не только международные, но и внутригосударственные отношения. О том, как применяются стандарты Международной организации труда в государствах - членах, о путях повышения эффективности норм международного права говорится в материалах МОТ: "Если рекомендации организации имеют положительные последствия, то можно было бы проводить прогрессивные достижения путем ратификации конвенций". 4 
Наиболее ярким выражением структурного сближения норм национального и международного права являются модельные законодательные акты. Их положение свидетельствует о роли международного права в регулировании национальных отношений. Рекомендательные по своей природе они содержат правовые стандарты, которые полностью или частично воспринимаются государствами в процессе законотворчества. Наконец, свидетельством влияния международного права на право РК являются также акты, непосредственно не связанные с приведением в действие норм международного права на территории РК, но которые наше государство ввело у себя для регламентации аналогичных отношений. Такое происхождение имеют нормы казахстанского патентного законодательства. Еще до присоединения к Парижской конвенции от охране промышленной собственности 1883 г. Республикой Казахстан в Патентном законе 1992 г. и законе "О товарных знаках обслуживания" 1993 г. были учтены нормы международных конвенций по этому вопросу (понятия патента, порядок выдачи патента, приоритетный срок, патентные поверенные, патентное ведомство и др.).

Следует заметить, что некоторое международные конвенции, которые еше не ратифицированы РК, применяются для регулирования определенных правоотношений в нашем государстве, примером может служить Венская конвенция 1980 г. о международной куплепродаже товаров, которая еще не ратифицирована РК, но регулирует отношения международной купли-продажи, если коммерческое предприятие одной из сторон находится на территории страны-участницы конвенции, либо если коллизионная норма прямо указывает на применение права страны-участницы конвенции.

Американский ученый А.Барнес указывает, что "Венская конвенция о договорах международной купли-продажи товаров была задумана как единообразный кодекс для международных контрактов, обеспечивающий унификацию и стабильность сделок или контрактов, заключенных в США с различными государствами.

Конвенция содержит правила заключения международных контрактов и регулирует перемещение товаров по этим контрактам. Она действует с 1 января 1988 г. для США, которые ее ратифицировали.

Конвенция применяется только к международным контрактам и только к коммерческой торговле товарами. Она применяется к таким

${ }^{4}$ The ILO, standart settings and globalisation. - Geneva. 1997 r., P.22 
сделкам, участниками которых являются государства, подписавшие и ратифицировавшие конвенцию, или когда Стороны согласились о ее применении" 5 .

Из приведенных выше примеров можно сделать вывод о том, что влияние международного права на право РК выражается в основном в появлении в казахстанском законодательстве новых норм или исключении некоторых действующих норм, не соответствующих основным принципам международного права или принятым на себя международным обязательствам. Однако воздействие международного права на этом не ограничивается. Влияние международного права на законодательство РК проявляется и без издания национальных законодательных актов, в силу самого факта утверждения (ратификации) нового международного договора. Согласно ст. 4 Конституции РК 1995 г. нормы ратифицированного международного договора применяются непосредственно, за исключением случаев, когда для его применения требуется издание закона.

Все эти примеры свидетельствуют о влиянии международного права на право РК и о разнообразии форм такого влияния.

Теперь поговорим о влиянии национального права на международное право. Принципы взаимодействия права РК и международного права отражены в Конституции РК 1995 г. в ст.4, в которой, в частности, говорится, что международные договоры, ратифицированные РК, имеют приоритет перед ее законами и применяются непосредственно, кроме случая, когда из международного договора следует, что для его применения требуется издание закона.

В Указе Президента РК "О порядке заключения, исполнения и денонсации международных договоров РК" от 12 декабря 1995 г. разработана строгая система проведения правовой экспертизы содержания международных договоров на предмет соответствия их Конституции РК (ст.ст. 6, 12, 14). Проекты международных договоров подлежат обязательной правовой экспертизе в Министерстве юстиции РК и согласованию в МИД РК

Национальное право оказывает двоякое влияние на международное право. Во-первых, это влияние содержания норм национального права на содержание норм международного права. Такое влияние можно назвать материальным. Во-вторых, это влияние норм внутри-

5 Barness A.,Dworkin T. Law for business. Homewood. 1991 г., P. 886.

6 Сафопова О.Н. Республика Казахстан в системе международных договоров.//Мысль, 1998 г., № 4. С.5-9 
государственного права, касающихся порядка создания норм международного права, на действенность норм международного права. Такое влияние можно назвать процессуальным.

Какие же нормы права РК влияют на содержание норм международного права? Прежде всего, принципы внешней политики государства, закрепленные в их основных законах. Конституция РК 1995 г. в ст.8 определяет следуюшие принципы внешней политики нашего государства "РК уважает принципы и нормы международного права, проводит политику сотрудничества и добрососедских отношений между государствами, их равенства и невмешательства во внутренние дела друг друга, мирного разрешения международных споров, отказывается от применения первой вооруженной силы".

Законодательство, являясь одной из важнейших форм правотворческой деятельности государств - субъектов международного права, оказывает большое воздействие на международное право. Формы такого воздействия многообразны:

влияние законодательства на создание новых международно-правовых норм;

влияние законодательства на углубление содержания, расширение сферы действия, на эффективность международно-правовых норм;

влияние законодательства на процесс устранения из международного права устаревших институтов и норм;

влияние "параллельного" национального законодательства на формирование и становление международно-правовых норм, а также влияние через comitas gentium (международную вежливость). ${ }^{7}$

Внутригосударственные законы, касающиеся дипломатических привилегий и иммунитетов, порядка заключения международных договоров и другие, регулирующие деятельность государства в международных отношениях, оказывают воздействие на международное право. В РК принят целый ряд таких законодательных актов: Указ Президента, имеющий силу закона, "О порядке заключения, исполнения и денонсации международных договоров РК" от 12.12.1995 г., закон РК "О дипломатической службе" от 12.11.1997 г., Указ Президента РК, имеющий силу закона, "Об использовании воздушного пространства и деятельности гражданской авиации РК" от

${ }^{7}$ Сафонова О.Н., Абдрасулов Е.Б. Принципы и условия взаимодействия права Республики Казахстан и международного права // Прикладные аспекты обеспечения реформ в сфере экономики и права Казахстана. Усть-Каменогорск, Издательство ВКГУ, 1999 г., С.13 
20.12.1995 г., Закон РК "О государственной границе РК" от 13.01.1993 г. и другие. Тесное взаимодействие международного и внутригосударственного права при регулировании процесса заключения международных договоров обусловило возникновение нормы международного права, согласно которой : "Государство не вправе ссылаться на то обстоятельство, что его согласие на обязательность для него договора было выражено в нарушение того или иного положения его внутреннего права, касающегося компетенции заключать договоры, как на основание недействительности его согласия, если только даннное нарушение не было явным и не касалось нормы его внутреннего права особо важного значения"8.

Влияние внутреннего права на международное право все более очевидно. Международное право дифференцируется на отрасли не без воздействия отраслевой структуры национальных правовых снстем. Сближаются предметы правового регулирования, соответствующие источники права. Внутреннее право обеспечивает, защищает и инициирует нормы международного права.

Нельзя не сказать о влиянии национального права на международное право в процессе применение его норм. Какие же способы существуют для соблюдения норм национального законодательства при применении норм международного права? Главным образом, отсылка в норме международного права к национальному праву соответствующего государства. Так, например, в международных договорах, когда в них предусматривается обязанность принять внутригосударственные меры, соответствующие законодательству сторон или делается ссылка на конституционную процедуру. Так, в Генеральном соглашении между Правительством РК и Правительством Королевства Саудовской Аравии о сотрудничестве в торгово-экономической, инвестиционной, технической и культурной областях, а также в области спорта и по делам молодежи от 27.09.1994 г., в ст. 8 ч. 1 сказано: "Настоящее соглашение вступаете силу после обмена нотами с уведомлением о выполнении всех необходимых процедур, предусмотренных законодательствами сторон"9.

Однако ни прямой рецепции внутригосударственного права правом международным, ни прямой трансформации норм национально${ }^{8}$ Венская конвенция о праве международных договоров, 1969 г., ч.1 ст.46 // Международное право в документах / Сост. Н.Т. Блатова. М., Международные отношения, 1992 г., С.85

9 Бғллетень международных договоров. 1995 г., 3 !. Алматы: Жеты - Жаргы, 1995 г., C. 47 
го права в международное право не может быть, так как нормы права отдельного государства не могут порождать международных прав и обязанностей.

В международной практике случаются отдельные случаи, которые условно можно было бы назвать косвенной трансформацией норм внутригосударственного права в нормы международного права. В настояшее время заключаются соглашения о введении в действие единообразного законодательства по тому или иному вопросу. В процессе приведения в действие норм международного права могут возникнуть несогласованности и противоречия между содержанием норм международного права и норм внутригосударственного права, такие случаи носят название коллизий. Эти коллизии должны разрешаться в рамках национального права. Возможности и пути их решения зависят не только от приемлемых государствами юридических способов, но и от характера их внутренней и внешней политики, экономического развития и т. д.

Таким образом, взаимодействие правовых систем проявляется в согласованном регулировании отношений, относящихся к совмещенному предмету регулирования. Принципиальное значение имеет разграничение понятий: право государства, как совокупность, создаваемых данным государством правовых норм и право, применяемое в государстве, как совокупность всех правовых норм, которые подлежат реализации в сфере внутригосударственных отношений и могут действовать в пределах юрисдикции соответствующего государства и компетенции его органов. Второе понятие шире первого, т.к. оно охватывает и применимые международные нормы, и отдельные нормы права иностранных государств.

Естественно, что для такого применения нормы, принадлежащие к различным правовым системам, должны обладать юридической совместимостью.

В связи с рассмотрением проблемы о разграничении понятий "право государства" и "право, применяемое в государстве" требуют уточнения вопросы об источниках права и о квалификации нормативных комплексов, действующих на межсистемной основе.

Каждая правовая система имеет свои источники, которые обладают способностью выполнять функции в рамках другой правовой системы, не переходя в нее.

Что касается нормативных комплексов, действующих на межсистемной основе, то предпринимаемые попытки конструирования 
межсистемных отраслей и межсистемных институтов не совсем оправданы. Такие группы разносистемных норм можно обозначать как правоприменительные комплексы.

В нашей практике типичными являются двусоставные правоприменительные комплексы из норм национального законодательства и норм международных договоров. Вместе с тем, получили распространение правоприменительные комплексы из норм международных договоров и норм иностранного права. Принципы и условия взаимодействия национального права РК и международно-правовых норм в процессе их применения - это другой аспект проблемы соотношения национального и международного права, представляющий большой интерес, как в теоретическом, так и в практическом отношении.

С теоретической точки зрения особенность данного аспекта связана с тем, что предмет регулирования в международном и национальном праве частично совпадает, поскольку одни и те же вопросы могут регулироваться нормами и международного и внутригосударственного права, в то время как методы регулирования различны. Именно поэтому приходится сопоставлять нормы международного права, подлежащие применению внутри страны, и те нормы внутригосударственного права, с помощью которых они приводятся в действие, искать согласованности тех и других норм и устранять противоречия между ними.

В литературе по международному праву можно встретить интересную классификацию. Предлагаются различные варианты:

внутригосударственное право, предписанное международным правом;

внутригосударственное право, дозволенное международным праВом;

внутригосударственное право, иррелевантное международному праву;

внутригосударственное право, противоречащее международному праву ${ }^{10}$.

И в заключении необходимо обозначить проблему суверенитета государства в ее международно-правовом аспекте, т.к. она непосредственным образом взаимосвязана с нашим вопросом.

В последние годы в юридической науке появились различные теории суверенитета: концепция "расщепленного" суверенитета, кон-

${ }^{10}$ Оппенгейм Л. Международное право, т.1 М., 1948 г., С.62. 
цепция множественности субъектов суверенитета, абсолютизация суверенитета, теория неограниченного суверенитета. Согласна, что "суть государственного суверенитета... выражается в верховенстве государства на всей территории и его независимости в международных отношениях...понятие суверенитета в связи с расширением международноге сотрудничества значительно изменилось. Многие вопросы, входйвшие ранее во внутреннюю компетенцию государства, стали предметом международно-правового регулирования. Усиление роли международного права ведет к дальнейшему сужению суверенитета... . Следовательно, государства, оставаясь суверенными, ограничивают на основе взаимности, в т.ч. и в пользу международных организаций, объем своего суверенитета"11.

Эту же точку зрения разделяют участники круглого стола "Суверенитет в государственном и международном праве" в журнале "Советское государство и право", где, в частности, говорится следующее: "Государственный суверенитет не абсолютен, а относителен...Государственный суверенитет можно определить как исходящую от народа верховную власть, состоящую в самостоятельном осуществлении государством своих функций в рамках национального и международного права" 12 .

В казахстанской науке большой вклад в разработку концепции государственного суверенитета внес А.К.Котов. Он предложил переосмыслить понятие "государственный суверенитет" в свете новых международных и внутренних социальных парадигм, показал постепенный процесс изменения научных воззрений на роль суверенитета государства в условиях роста авторитета международного права. Он указывает, что "суверенитет рационально может быть понят не столько, и не только в политико-правовых определениях верховенства и независимости, сколько в основной совокупности своих социальных определений и объективного интегрирующего и жизнеутверждающего предназначения для общества...суверенитет Казахстана есть сверхвременное начало целостности казахстанского общества, объединяющее своим верховенством постоянно проживающих на территории современного Казахстана равноправных граждан в

11 Сабикенов С.Н. Проблемы государственного и национального суверенитета в условиях РК. // Проблемы формирования новой национальной правовой системы РК. Алматы. НИ и РИО АВШ МВД РК, 1993 г.., С.27

12 Лукашук И.И. Материалы круглово стола "Суверенитет в государственном и международном праве" // Советское государство и право. 1991. № 5 
один казахстанский народ, и обеспечивающее им собственной не подчиненностью власти других государств и международно-правовой совместимостью, независимые национальное и свободное человеческое существование" 13 .

Таким образом, наличие государственного суверенитета не входит в противоречие с признанием примата международного права. Государства самостоятельно решают вопрос об ограничении своего суверенитета в пользу международных межправительственных организаций (примером является Европейское Сообщество), либо в силу участия в международных многосторонних договорах. Государственный суверенитет не помеха, а предпосылка свободного развития нашей страны в условиях ее успешного вхождения в мировое сообщество.

${ }^{13}$ Котов A.K. Государственый суверенитет РК: политико-правовой анализ становления и проблемы национально-государственного развития. Диссертация д.ю.н. 12.00.01 г., Алматы. 1997. 